\title{
INCIDENCE OF HIP FRACTURE IN THE EASTERN MEDITERRANEAN REGION- A SYSTEMATIC REVIEW AND META-ANALYSIS
}

\author{
Mohammad Zamani1 ${ }^{1}$ Seyed Mohammad Reza Esmaeilnejad-Ganji², Seyed Mokhtar Esmaeilnejad-Ganji ${ }^{3}$
}

${ }_{1}^{1}$ Student Research Committee, School of Medicine, Babol University of Medical Sciences, Babol, Iran.

${ }^{2} \mathrm{MD}$, Boston University School of Medicine, Boston, USA.

${ }^{3}$ Associate Professor, Clinical Research Development Centre, Shahid Beheshti Hospital, Babol University of Medical Sciences, Babol, Iran.

\begin{tabular}{l}
\hline ABSTRACT \\
BACKGROUND \\
Hip fracture is a major health concern with high rates of mortality and disability. The purpose of this study was to conduct a \\
systematic review and meta-analysis on the incidence of hip fracture in the Eastern Mediterranean Region (EMR).
\end{tabular}

\section{METHODS}

We searched the databases of PubMed, Scopus, Web of Science and Index Medicus for the EMR for observational studies reporting the incidence of fracture in the EMR countries, which were published from inception to September 2018 with no language restriction. Study selection and data extraction were conducted independently by two reviewers.

\section{RESULTS}

After applying inclusion and exclusion criteria, 10 articles were finally included in this study. The overall pooled crude incidence rate of hip fracture in the EMR was estimated to be 107.4 per 100,000 population/year (95\% confidence interval [CI]: 83-131.8). Analysis also showed that the overall pooled age-standardized rate was 174.4 per 100,000 population/year (95\% CI: 103.9-244.9). Lebanon had the highest crude incidence rate (140.1 per 100,000 population/year), and Kuwait had the lowest rate (21.9 per 100,000 population/year). Age-standardized rate for males was 121.3 per 100,000/year (95\% CI: 80.8-161.7) and for females was 227.4 per 100,000/year (95\% CI: 129-325.9). The overall crude incidence for traumatic fracture was estimated to be 79.2 per 100,000/year (95\% CI: 21.8-136.6).

\section{CONCLUSIONS}

A considerable incidence rate was seen for hip fractures. There were also significant variations in the incidence of different countries of the EMR. Implementing preventive measures against fractures is needed in the region.

HOW TO CITE THIS ARTICLE: Zamani M, Ganji SMRE, Ganji SME. Incidence of hip fracture in the eastern mediterranean region- a systematic review and meta-analysis. J. Evolution Med. Dent. Sci. 2019;8(14):1188-1195, DOI: 10.14260/jemds/2019/262

\section{BACKGROUND}

Fractures can happen in any bone due to trauma (e.g. accidents) or non-traumatic mechanisms (e.g. medical conditions such as osteoporosis). Fractures can be either displaced or non-displaced based on the type and severity of imported energy, and each one has its own prognosis.(1-4)

Bone fractures occur mostly in young or older people. Its epidemiology varies between different communities, as well as between regions within the same country. (5-7) Hip fracture is a serious health issues, because it is strongly associated with mortality, disability and high medical costs.(8-10) In 1990, 1.6 million hip fractures was estimated in world, expecting to increase to 6.3 million by 2050.(11) Its medical costs were calculated US $\$ 153$ billion in 1997 , increasing to US $\$ 446.3$ billion by $2050 .(12)$

The Eastern Mediterranean Region (EMR) consists of 22 developing countries with population of about 583 million people.(13)

'Financial or Other Competing Interest': None.

Submission 17-02-2019, Peer Review 22-03-2019,

Acceptance 28-03-2019, Published 08-04-2019.

Corresponding Author:

Dr. Seyed Mokhtar Esmaeilnejad-Ganji,

Department of Orthopedics,

Babol University of Medical Sciences,

Ganjafrooz Street, Babol,

Mazandaran, Iran,

E-mail: smsnganji@yahoo.com

DOI: $10.14260 /$ jemds $/ 2019 / 262$

\section{(c) $(1)$}

Studies report variable rates of incidence for hip fracture in these countries for example, a study from Kuwait reported an age-standardized rate of 48.4 per 100,000 population/year.(14) On the other hand, a study from Morocco stated that age-standardized rate of hip fracture is 69 per 100,000 population/year.(15) The outcomes of fracture are also important. One investigation reported a mortality rate of $7 \%$ for hip fracture in the Lebanese population after one year and $18 \%$ after 5 years.(16) Another survey from Iran reported a death rate of $11.2 \%$ during 2007-2008.(17) Our recent metaanalysis showed that the prevalence of osteoporosis has increased over the last years in the EMR(18) therefore, osteoporotic fractures will probably become more prevalent and become an even greater concern for this region.

Epidemiological studies on fracture should be helpful for the healthcare providers to better plan for its control and prevention. While the fracture incidence has been evaluated in different studies in the EMR, we believe that a systematic review and meta-analysis will help long-term planning by policy makers.

\section{METHODS}

\section{Information Sources and Search Strategy}

A literature search was conducted from the bibliographic databases of PubMed, Scopus, Web of Science and Index Medicus for the EMR published from the inception to 31 September 2018 with no language restriction. The related terms were searched in the Medical Subject Headings (MeSH) database, and finally, the keywords included "fracture" OR 
"fractures" OR "broken" AND "epidemiology" OR "incidence" AND "Afghanistan" OR "Bahrain" OR "Djibouti" OR "Egypt" OR "Iran" OR "Iraq" OR "Jordan" OR "Kuwait" OR "Lebanon" OR "Libya" OR "Morocco" OR "Oman" OR "Palestinian" OR "Pakistan" OR "Qatar" OR "Saudi Arabia" OR "Somalia" OR "Sudan" OR "Syria" OR "Tunisia" OR "United Arab Emirates" OR "Yemen". The search was limited to Title/Abstract. Name of countries was limited to affiliation as well. Reference lists of the related reviews and the retrieved papers were manually searched for additional materials.

\section{Inclusion and Exclusion Criteria}

We included all observational studies reporting the incidence of hip fracture in the general population or a community. We excluded those studies that did not cover all cases of hip fracture in a region. For example, a registry study covering $100 \%$ of the patients was considered as a reference and studies using such database were included for further analysis. On the other hand, we excluded any study that was conducted in only one hospital that was not a referral center for fractures. We also excluded those studies that evaluated incidence over a period of less than 1 year. Other exclusion criteria were as follows:

1. Reviews, case reports, editorials, letter to the editors and abstracts from conferences.

2. Duplicate articles or evaluating the same sample.

3. Case-control studies.

4. Studies included subjects with other specific diseases (e.g., cancer, haemophilia, etc.)

5. Surveys without clear methodology or results.

6. Full-texts not being available.

\section{Study Selection and Data Extraction}

Two reviewers screened independently the titles and abstracts of all references for potential suitability. Full-texts of the potential articles were obtained for the final assessment of suitability for inclusion. Any discrepancies pertaining to the inclusion of articles were resolved by consensus with a third reviewer. Data were assessed and extracted from the studies and finally included for analysis into a Microsoft Excel spreadsheet. The following data were extracted: author's name, study location, study date, publication date, characteristics of the samples (including gender, age), sample size, overall and sex-specific incidence rate of hip fracture (crude rate and age-standardized rate), and fracture type (traumatic or non-traumatic). We tried to split the studies by fracture type and study date as much as possible, and each was considered as a separate report. The incidence rates were extracted as cases per 100,000 persons/year from each study. Google Translate was used to translate non-English reports. We excluded duplicates and only selected those with the most comprehensive details.

\section{Study Outcomes and Statistical Analysis}

The data extracted from the retrieved articles were combined to give the pooled incidence rates. The pooled incidence rates were presented as per 100,000 population/year and $95 \%$ confidence interval (CI). The heterogeneity between the studies was evaluated by $\mathrm{I}^{2}$ statistic. We used fixed- and random-effects models to calculate the pooled estimates when $\mathrm{I}^{2}$ was $<50 \%$ and $>50 \%$, respectively. Subgroup analyses were performed according to country, gender (male and female), study period $(\leq 2006,>2006)$, and type of fracture (traumatic). Splitting the study date into $\leq 2006$ and $>2006$ was mainly based on the distribution of the number of reports in each period category. In order to determine a significant difference between the groups, we relied on coverage of $95 \%$ CI. All statistical analyses were done using STATA (Stata Corp, College Station, TX, USA).

\section{RESULTS}

\section{Search Results, Study Selection and Characteristics}

The initial search in the databases identified a total of 2027 citations and 1252 remained after removing duplicates. After evaluating the title and/or abstract, 1228 articles were excluded because of failure to meet the inclusion criteria. Full-text of the remaining 24 papers were assessed for eligibility; 10 eligible articles were included in the final analyses. The results of search strategy is shown in a flow diagram according to the PRISMA (Preferred reporting items for systematic review and meta-analysis) guideline (19) (Figure 1). The characteristics of the included articles are summarized in Table 1.

\section{Estimated Incidence of Fracture \\ - Overall}

All of 10 articles included to this systematic review reported the crude incidence rate, but age-standardized rate was found in only 4 papers. The overall pooled crude incidence rate of fracture in the EMR was estimated to be 107.4 per 100,000 population/year (95\% CI: 83-131.8; $\mathrm{I}^{2}=99.9 \%$; $\mathrm{p}=0.000$ ) (Figure 2). Analysis also showed that the overall pooled agestandardized rate was 174.4 per 100,000 population/year $\quad\left(95 \%\right.$ CI: $103.9-244.9 ; \quad I^{2}=99.5 \%$; $\mathrm{p}=0.000$ ) (Figure 3). Analysis of 3 nationwide articles indicated an overall pooled crude incidence rate of 111.4 per 100,000 population/year $(95 \%$ CI: 52-170.8; $\mathrm{I}^{2}=99.9 \%$; $\mathrm{p}=0.000$ ) in the EMR. The overall pooled agestandardized rate for nationwide studies was also estimated to be 187.4 per 100,000 population/year (95\% CI: 59.2-315.5; $\mathrm{I}^{2}=99.7 \%$; $\mathrm{p}=0.000$ ).

\section{- Country-Based Incidence}

Iran had the highest number of articles $(\mathrm{n}=5)$, and other countries (Kuwait, Lebanon, Morocco, Oman and Saudi Arabia) each only had 1 article. The pooled crude and age-standardized incidence rates analysed for each country are reported in Table 2. Lebanon had the highest crude incidence rate $(140.1$ per 100,000 population/year), but Kuwait had the lowest rate (21.9 per 100,000 population/year).

\section{- Gender}

All of 10 articles reported the crude incidence of hip fracture in males in the EMR and the overall pooled incidence rate was estimated as 97.9 per 100,000 population/year $\quad\left(95 \% \quad\right.$ CI: $74.7-121.1 ; \quad I^{2}=99.7 \%$; $\mathrm{p}=0.000$ ). The age-standardized rate in males was reported in 5 articles and the overall pooled incidence was estimated to be 121.3 per 100,000 population/year (95\% CI: 80.8-161.7; I²=98.2\%; p=0.000). Regarding females, the same number of articles reported the crude and age-standardized incidence rates for hip fracture in 
the EMR. The overall pooled crude incidence rate was 113.8 per 100,000 population/year (95\% CI: $87.7-140$; $\mathrm{I}^{2}=99.7 \% ; \mathrm{p}=0.000$ ). In addition, the overall pooled agestandardized rate was estimated to be 227.4 per 100,000 population/year $\quad\left(95 \% \quad\right.$ CI: $129-325.9 ; \quad I^{2}=99.3 \%$; $\mathrm{p}=0.000$ ). Figures 4 and 5 show the forest plots of the pooled data related to gender.

\section{- Study Date}

Six papers were in the $\leq 2006$ group and 5 studies were conducted after 2006. The pooled crude incidence of fracture for the first period was 123.3 per 100,000 population/ year (95\% CI: 47.4-199.1; I2=99.8\%; $\mathrm{p}=0.000)$. In relation to second group $(>2006)$, the overall crude incidence rate was 97.1 per 100,000 population/year (95\% CI: 54.5-139.7; I2=100\%; $\mathrm{p}=0.000$ ).

\section{- Fracture Mechanism}

With respect to the mechanism of fracture, 4 articles reported the fractures to be due to trauma, but 6 articles did not specify the mechanism. After pooling the data related to traumatic fracture, the overall crude incidence was estimated to be 79.2 per 100,000 population/year (95\% CI: 21.8-136.6; $\mathrm{I}^{2}=99.9 \%$; $\mathrm{p}=0.000$ ) in the EMR.

\begin{tabular}{|c|c|c|c|c|c|c|c|c|c|c|c|c|c|c|}
\hline 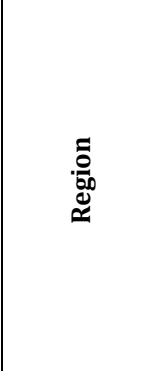 & 咅 & 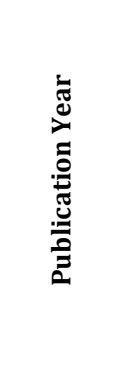 & 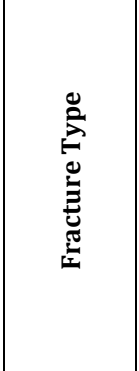 & 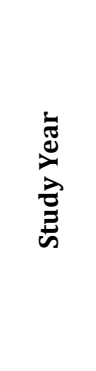 & $\stackrel{8}{\alpha}$ & 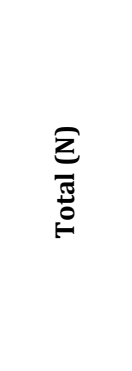 & 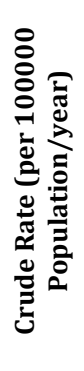 & 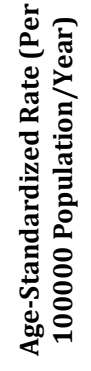 & $\begin{array}{l}\sum_{0} \\
\frac{0}{\pi} \\
\sum\end{array}$ & 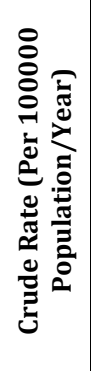 & 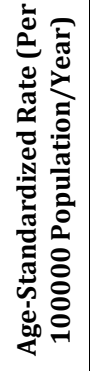 & 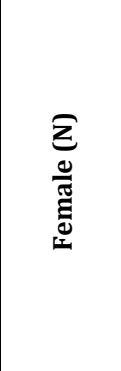 & 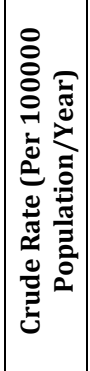 & 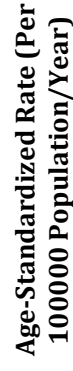 \\
\hline \multicolumn{15}{|c|}{ Iran } \\
\hline Kermanshah & Beyranvand & 2009 & \begin{tabular}{|c|} 
Not \\
specified
\end{tabular} & $\begin{array}{c}2007- \\
2008 \\
\end{array}$ & $\geq 50$ & 114206 & 141 & 194 & 58653 & 150.4 & 181.1 & 55553 & 131.7 & 214.6 \\
\hline Nationwide & $\begin{array}{c}\text { Ahmadi- } \\
\text { Abhari(20) }\end{array}$ & 2007 & \begin{tabular}{|c|} 
Accidental \\
injuries
\end{tabular} & 2005 & $\geq 50$ & 8845000 & 115.4 & - & 4361000 & 115.2 & - & 4484000 & 115.6 & \\
\hline $\begin{array}{c}\text { Nine } \\
\text { provinces }\end{array}$ & Abolhassani(21) & 2006 & $\begin{array}{c}\text { Fall- } \\
\text { related }\end{array}$ & 2003 & $\geq 20$ & 5074178 & 30.4 & - & 2581714 & 31.8 & - & 2492464 & 29 & - \\
\hline Tabriz & Aliasgarzadeh $^{(22)}$ & 2009 & $\begin{array}{c}\text { Not } \\
\text { specified }\end{array}$ & 2006 & $>50$ & 234142 & 175.1 & - & 121647 & 175.9 & - & 112495 & 174.2 & \\
\hline Zanjan & Valizadeh & 2008 & $\begin{array}{c}\text { Not } \\
\text { specified }\end{array}$ & $\begin{array}{c}2006- \\
2007 \\
\end{array}$ & $\geq 50$ & 139109 & 175.4 & 210.2 & 68627 & 190.9 & 206.5 & 70482 & 160.3 & 214.8 \\
\hline \multicolumn{15}{|c|}{ Kuwait } \\
\hline Nationwide & Azizieh & 2017 & $\begin{array}{c}\text { Not } \\
\text { specified } \\
\end{array}$ & $\begin{array}{c}2009- \\
2012 \\
\end{array}$ & $\begin{array}{l}0 \text { to } \\
>80 \\
\end{array}$ & 14448034 & 21.9 & 48.4 & 8754991 & 24.8 & 45.1 & 5693043 & 18.9 & 52.5 \\
\hline \multicolumn{15}{|c|}{ Lebanon } \\
\hline Nationwide & Sibai ${ }^{(23)}$ & $2011(\mathrm{~A})$ & $\begin{array}{c}\text { Not } \\
\text { specified }\end{array}$ & 2006 & $\geq 50$ & 394099 & 141.1 & 239.5 & 183929 & 88.1 & 109.7 & 210170 & 187.5 & 370.4 \\
\hline Nationwide & Sibai & 2011 (B) & $\begin{array}{c}\text { Not } \\
\text { specified }\end{array}$ & 2007 & $\geq 50$ & 388251 & 142.7 & 234.1 & 181199 & 106.5 & 134.1 & 207052 & 174.4 & 335.1 \\
\hline Nationwide & Sibai & 2011 (C) & $\begin{array}{c}\text { Not } \\
\text { specified }\end{array}$ & 2008 & $\geq 50$ & 394673 & 136.6 & 228.3 & 184197 & 105.3 & 128.7 & 210476 & 163.9 & 329.0 \\
\hline \multicolumn{15}{|c|}{ Morocco } \\
\hline Rabat & Maghraoui & 2005 & $\begin{array}{c}\text { Not } \\
\text { specified }\end{array}$ & 2002 & $\geq 50$ & 312461 & 48 & 69 & 153178 & 43.7 & 58.5 & 159283 & 52.1 & 80.7 \\
\hline \multicolumn{15}{|c|}{ Oman } \\
\hline $\begin{array}{c}\text { South } \\
\text { Sharqiya }\end{array}$ & Shukla & 2008 & Falling & $\begin{array}{l}2002- \\
2007 \\
\end{array}$ & $\geq 40$ & 120787 & 121.7 & - & 60978 & 114.8 & - & 59809 & 128.7 & - \\
\hline \multicolumn{15}{|c|}{ Saudi Arabia } \\
\hline Riyadh & AI-Nuaim(24) & 1995 & Traumatic & $\begin{array}{c}1990- \\
1991\end{array}$ & $>40$ & 204424 & 50.4 & - & 92848 & 54.9 & - & 111576 & 46.6 & - \\
\hline
\end{tabular}

\begin{tabular}{|c|c|c|c|c|}
\hline Country & $\begin{array}{c}\text { Crude Rate (Per 100,000 } \\
\text { Population/Year) }\end{array}$ & $\begin{array}{c}\text { 95\% Confidence } \\
\text { Interval }\end{array}$ & $\begin{array}{c}\text { Age-Standardized Rate } \\
\text { (Per 100,000/Year) }\end{array}$ & $\begin{array}{c}\text { 95\% Confidence } \\
\text { Interval }\end{array}$ \\
\hline Iran & 126.9 & $72.5-181$ & 203.1 & $183.3-222.9$ \\
\hline Kuwait & 21.9 & $21.1-22.7$ & 48.4 & $46.7-50.1$ \\
\hline Lebanon & 140.1 & $133.3-146.8$ & 233.8 & $222.6-245.1$ \\
\hline Morocco & 48 & $40.3-55.7$ & 69 & $58-80$ \\
\hline Oman & 121.7 & $121.6-121.8$ & - & - \\
\hline Saudi Arabia & 50.4 & $40.7-60.1$ & - & - \\
\hline \multicolumn{4}{|r}{ Table 2. Incidence of Hip Fracture by Countries in Eastern Mediterranean Region } \\
\hline Eastern Mediterranean Region & $83-131.8$ & $103.9-244.9$ \\
\hline \multicolumn{4}{|r}{} \\
\hline
\end{tabular}




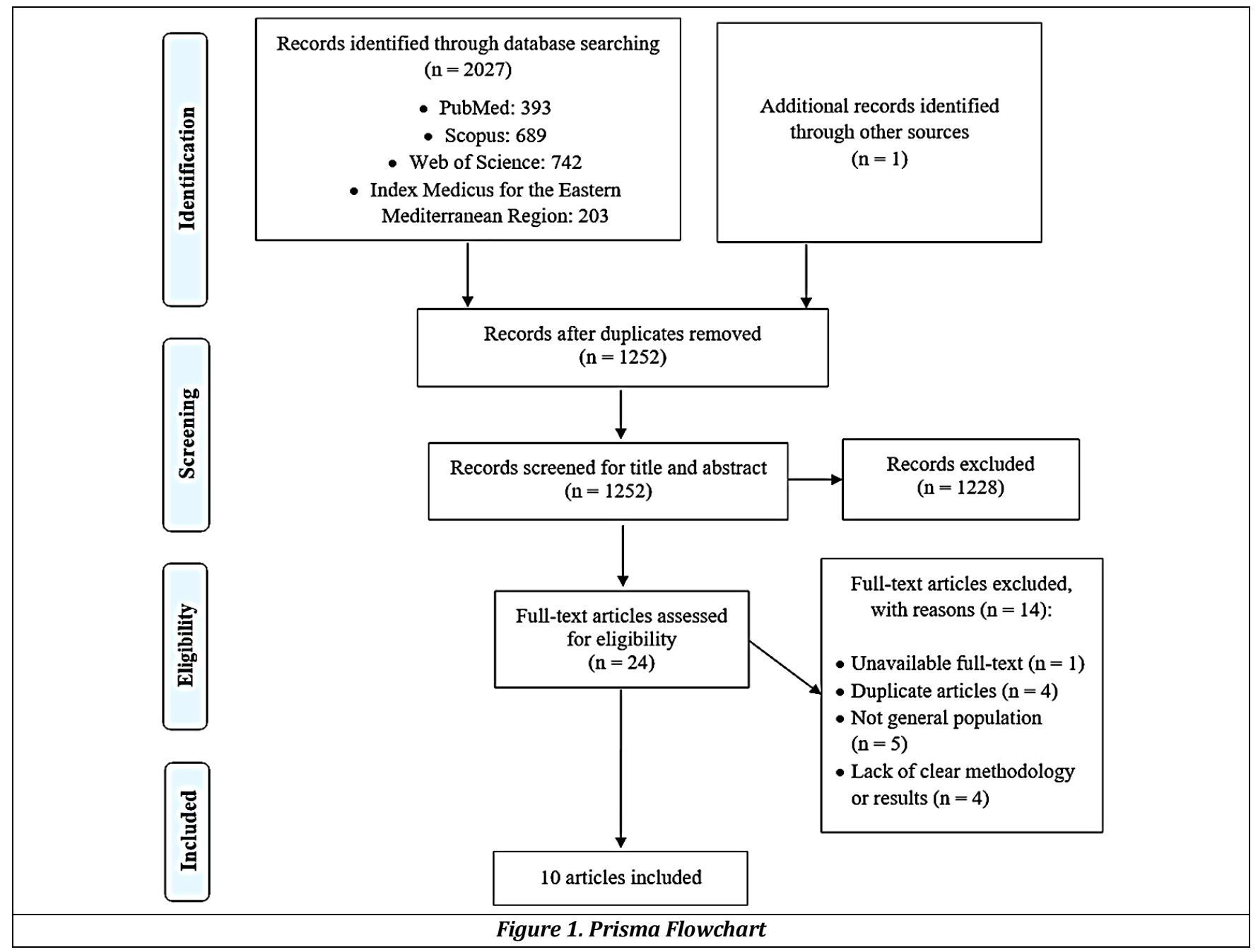

\begin{tabular}{|c|c|c|c|}
\hline \multicolumn{2}{|l|}{$\begin{array}{l}\text { Study } \\
\text { ID }\end{array}$} & \multirow{2}{*}{$\begin{array}{l}\text { Incidence per } \\
100000(95 \% \mathrm{CI}) \\
50.40(40.67,60.13)\end{array}$} & \multirow{2}{*}{$\begin{array}{l}\% \\
\text { Weight } \\
8.43\end{array}$} \\
\hline AI-Nuaim (1995) & $\rightarrow$ & & \\
\hline Abolhassani (2006) & - & $30.40(28.88,31.92)$ & 8.55 \\
\hline Ahmadi-Abhari (2007) & & $115.40(113.16,117.64)$ & 8.54 \\
\hline Aliasgarzadeh (2009) & & $175.10(158.17,192.03)$ & 8.21 \\
\hline Azizieh (2017) & - & $21.90(21.14,22.66)$ & 8.55 \\
\hline Beyranvand (2009) & & $141.00(119.24,162.76)$ & 8.00 \\
\hline Maghraoui (2005) & $\rightarrow$ & $48.00(40.32,55.68)$ & 8.48 \\
\hline Shukla (2008) & & $121.70(102.04,141.36)$ & 8.10 \\
\hline Sibai (2011 (A)) & & $141.10(129.38,152.82)$ & 8.38 \\
\hline Sibai (2011 (B)) & & $142.70(130.83,154.57)$ & 8.38 \\
\hline Sibai $(2011(C))$ & & $136.60(125.08,148.12)$ & 8.39 \\
\hline Valizadeh (2008) & & $175.40(153.41,197.39)$ & 7.99 \\
\hline Overall (I-squared $=99.9 \%, p=0.000$ & & $107.43(83.02,131.84)$ & 100.00 \\
\hline NOTE: Weights are from random effects analysis & & & \\
\hline-100 & & 00 & \\
\hline Figure 2. Forest Plot of Pooled Cr & nciden & Istern Mediterranear & egion \\
\hline
\end{tabular}




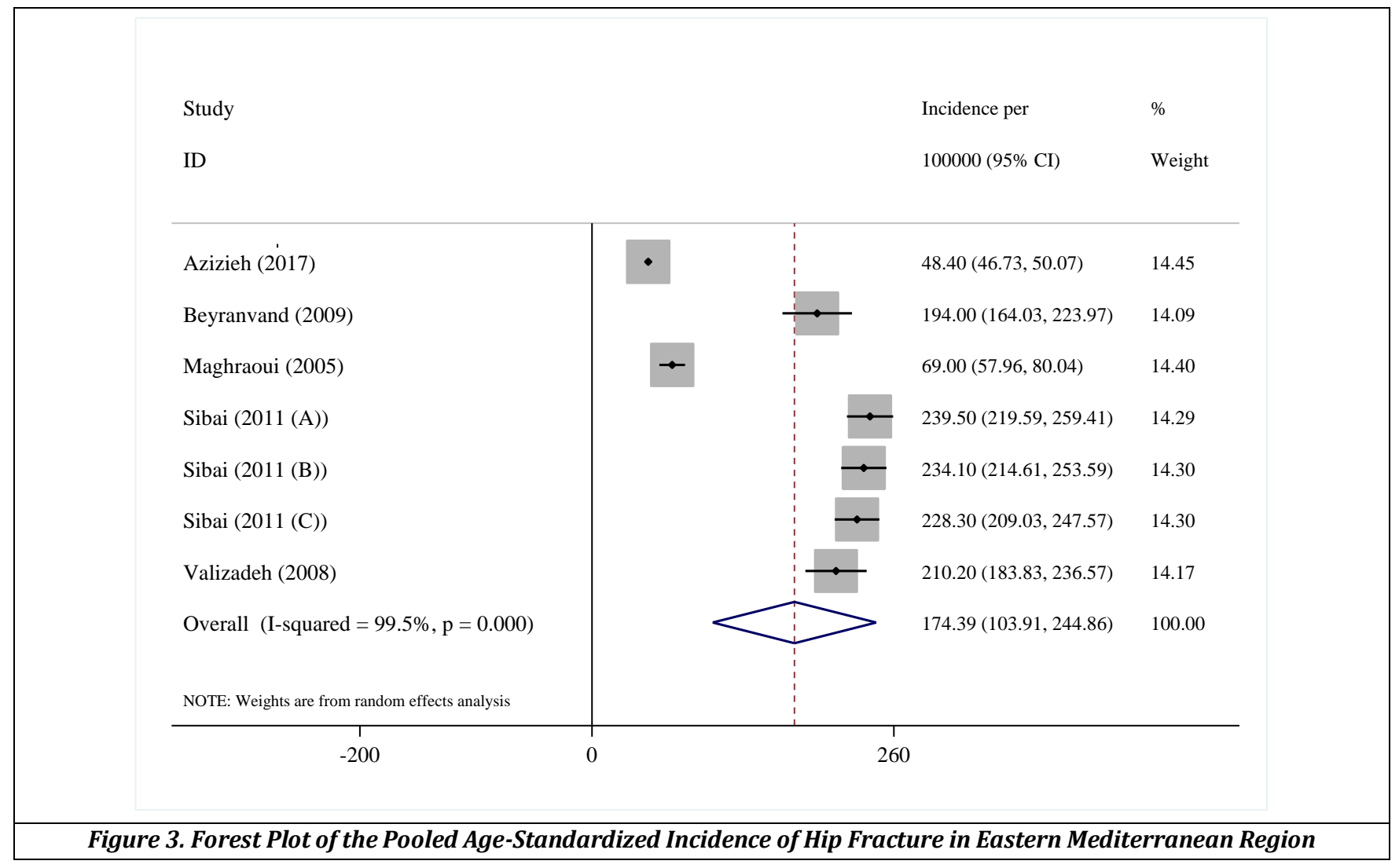

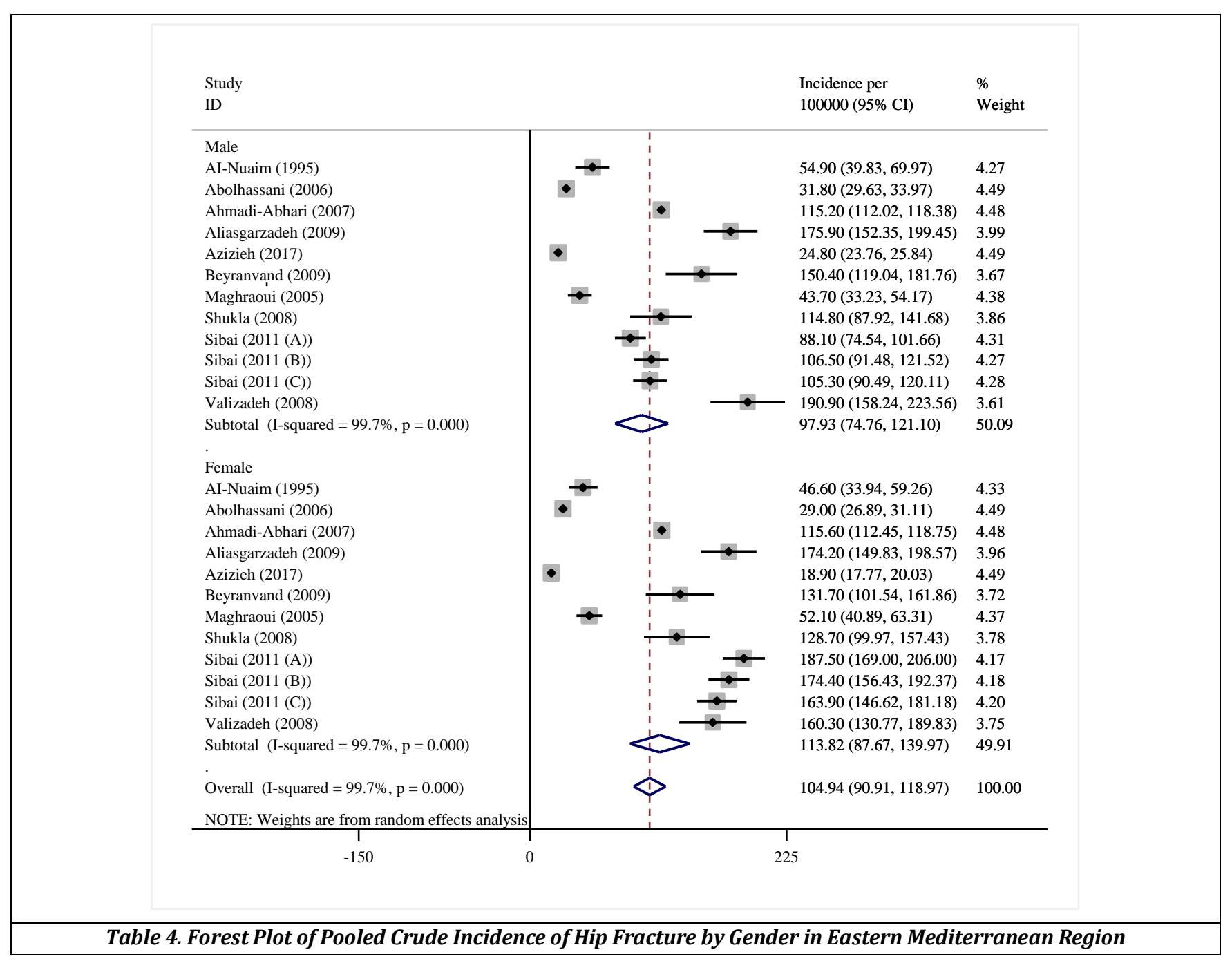




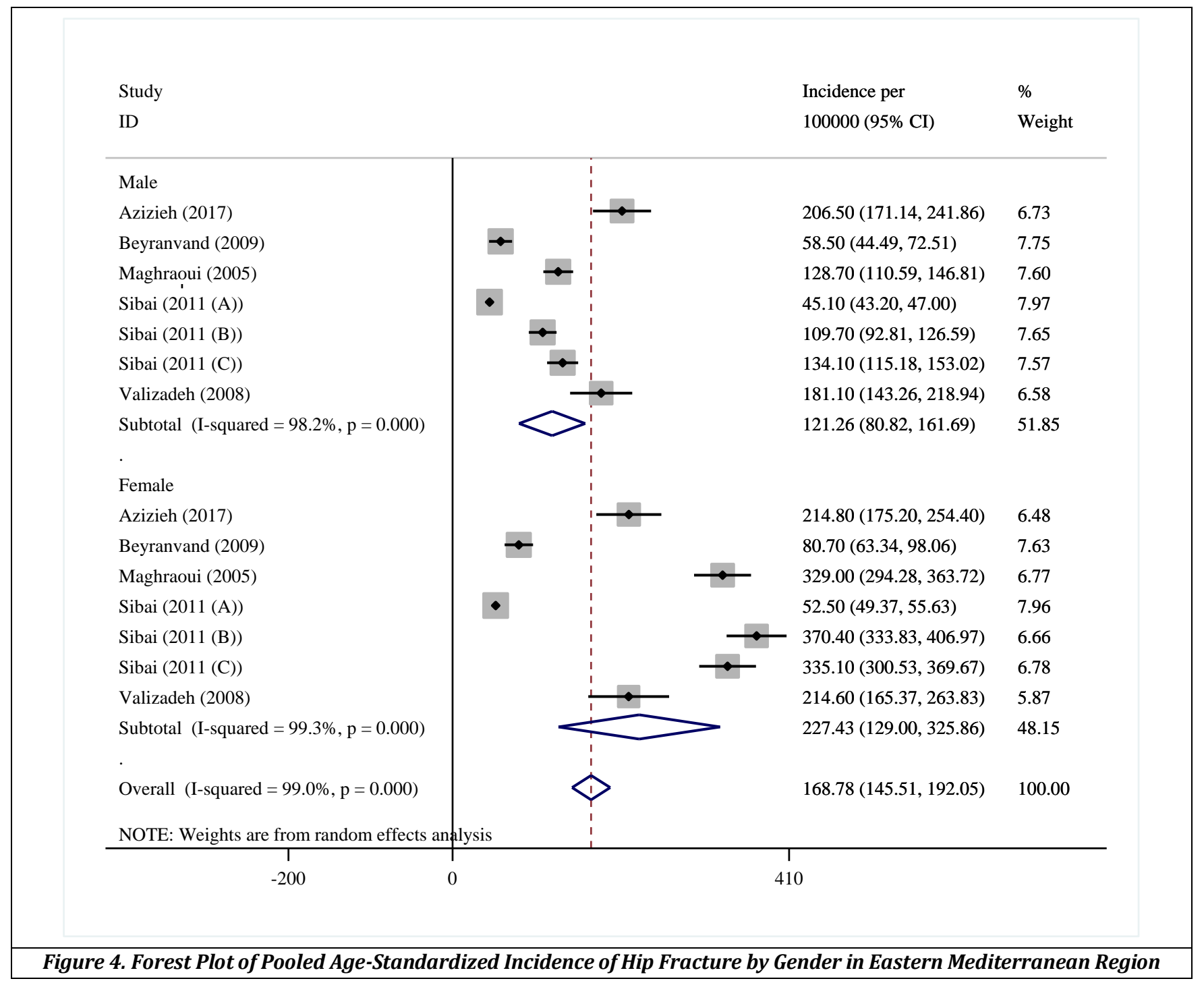

\section{DISCUSSION}

According to the results of this systematic review, the overall pooled crude incidence rate of hip fracture was 107 per 100,000 population/year in the EMR. The age-standardized rate was estimated to be 174 per 100,000 population/year. This rate was highest in Lebanon (crude rate of 140 per 100,000 population/year), and lowest in Kuwait (crude rate of 29 per 100,000 population/year). Analyses also showed that the overall age-standardized rates in males and females in the EMR were 121 and 227 per 100,000 population/year, respectively. The incidences of hip fracture in the EMR was lower in than most Western and European communities. For instance, a study by Amin et al.(25) In the US, stated that the incidence of hip fracture was 294 per 100,000 population/year. A study on 14 European countries indicated the predicted maximum hip fracture incidence rate from 376 per 100,000 population in Portugal to 1390 per 100,000 population in Sweden among females, and from 157 per 100,000 population/year in Portugal to 742 per 100,000 population/year in Sweden among males.(26) The results of this study, however, should be interpreted with caution because of differences in number of studies, being nationwide or local scale, and lack of reporting the age-standardized rate in some studies.

Following subgroup analysis, we did not find a significant difference between studies conducted before and after 2006 .
In the study by Azizieh.(14) From Kuwait, an increase of 3.9\% in annual incidence rates for all fractures was seen over 2009-2012. Shukla and Khandekar.(27) reported that incidence of hip fracture increased four-fold from 2002 to 2007. There have been differences in trends of hip fracture incidence worldwide. In most of the western countries and Oceania, there was initially a rise in the annual agestandardized rate, then followed by a decrease in recent years. An article from the United States, for example, reported that age-standardized annual incidence of hip fractures in females increased from 964 per 100,000 in 1986 to 1051 per 100,000 in 1995 , then decreased to 794 per 100,000 in 2005.(28) This trend was also seen in males, as the annual agestandardized rate increased from 392 per 100,000 to 457 per 100,000 from 1986 to 1995 , and decreased to 369 per 100,000 in 2005.(28) Another article reported this decline by 2015 as well.(29) On the other hand, it was found that in most of the Asian countries, the annual incidence of hip fracture has steadily increased 2- to 3-fold over the past three decades.(30) It should be noted, however, that changes in the pattern of fracture incidence depend on region, fracture type, and population characteristics.

Two main causes are responsible for hip fracture are low bone mineral density (related to osteoporotic fracture) and falling (related to traumatic fracture) ${ }^{(31,32)}$ Hip fracture is the most devastating type of osteoporotic fracture.(33) The 
relation between bone mineral density and fracture is understudied in the EMR.(16) The World Health Organization developed a fracture risk assessment tool (FRAX) to predict 10-year major osteoporotic and hip fracture probabilities, which has been reported in the EMR as well. $(6,34,35)$ Studies have demonstrated that osteoporosis management in subjects at high risk of hip fracture based on FRAX can be associated with a subsequent decrease in the rate of fracture.(36,37) Therefore, FRAX system is helpful for clinicians to prevent hip fracture. Of course, we should consider the fact that rate of fracture increases with age too. $\left.{ }^{(38,39}\right)$ therefore, it is necessary to pay more attention to the older patients.

About gender difference in fracture, it is stated that the risk of fracture is higher in females than in males, especially in postmenopausal females due to lower bone mineral density. Other reasons also exist, such as differences in bone size and bone strength between males and females.(40) Although fracture incidence is higher in females, males are prone to have worse outcomes and poorer treatment rates, and it is reported that mortality in males is as much as twice that of females. ${ }^{41,42)}$ However, it has been also expressed that because of more social and recreational activities, falling and traumatic fracture possibilities are higher in males than in females in some regions. $(17,43)$

A limitation of this study was that there were no data from 16 countries of the EMR, including Afghanistan, Bahrain, Djibouti, Egypt, Iraq, Jordan, Libya, Palestine, Pakistan, Qatar, Somalia, Sudan, Syria, Tunisia, United Arab Emirates and Yemen. Some countries, like Iran, have a fracture registry and it needs to be established in all countries of the EMR. Another limitation was lack of data related to age-standardized incidence rates in every included papers, therefore, we sometimes had to rely on crude data. We also witnessed high heterogeneity between the studies. This can be explained by differences in study date, the status of fracture registration in each country, population age and gender. We tried to decrease the heterogeneity by inclusion of studies which were population-based and representative of community. However, such heterogeneity is usually seen in the epidemiological studies and is not unexpected.(18,43)

\section{CONCLUSIONS}

According to results of this study, there are significant variations in the annual incidence of hip fracture between the different countries of the EMR. However, lack of information was observed from most of the countries. It is suggested that preventive measures need to be implemented against traumatic and non-traumatic fractures in these countries by the relevant authorities. We also encourage all countries of the EMR to establish a national fracture registry.

\section{REFERENCES}

[1] Wade SW, Strader C, Fitzpatrick LA, et al. Sex-and agespecific incidence of non-traumatic fractures in selected industrialized countries. Arch Osteoporos 2012;7:219-27.

[2] Leucht P, Fischer K, Muhr G, et al. Epidemiology of traumatic spine fractures. Injury 2009;40(2):166-72.
[3] Tsai CH, Fong YC, Chen YH, et al. The epidemiology of traumatic humeral shaft fractures in Taiwan. Int Orthop 2009;33(2):463-7.

[4] Ganji SME, Baghianimoghadam B, Ahangar SK, et al. Epidemiology and patterns of trauma in children. Trauma Monthly 2017;22(4):e34669.

[5] Hedström EM, Svensson 0, Bergström U, et al. Epidemiology of fractures in children and adolescents. Increased incidence over the past decade: a population-based study from northern Sweden. Acta Orthop 2010;81(1):148-53.

[6] Kanis JA, Oden A, McCloskey EV, et al. A systematic review of hip fracture incidence and probability of fracture worldwide. Osteoporos Int 2012;23(9):223956.

[7] Mohseni M, Janmohammadi N, Zamani M, et al. A survey of non-fatal road traffic accidents in Babol, Northern Iran. Trauma Monthly 2018;23(6):e66513.

[8] Sheehan K, Sobolev B, Chudyk A, et al. Patient and system factors of mortality after hip fracture: a scoping review. BMC Musculoskelet Disord 2016;17:166.

[9] von Friesendorff M, McGuigan FE, Wizert A, et al. Hip fracture, mortality risk, and cause of death over two decades. Osteoporos Int 2016;27(10):2945-53.

[10] Carpintero P, Caeiro JR, Carpintero R, et al. Complications of hip fractures: a review. World J Orthop 2014;5(4):402-11.

[11] Gullberg B, Johnell 0, Kanis JA. World-wide projections for hip fracture. Osteoporos Int 1997;7(5):407-13.

[12] Johnell 0 . The socioeconomic burden of fractures: today and in the 21st century. Am J Med 1997;103(2A):S20-S25.

[13] http://www.emro.who.int/entity/aboutus/index.html.

[14] Azizieh FY. Fractures in Kuwait: incidence and distribution. Risk Manag Healthc Policy 2017;10:11725.

[15] El Maghraoui A, Koumba BA, Jroundi I, et al. Epidemiology of hip fractures in 2002 in Rabat, Morocco. Osteoporos Int 2005;16(6):597-602.

[16] Maalouf G, Gannagé-Yared M, Ezzedine J, et al. Middle East and North Africa consensus on osteoporosis. J Musculoskelet Neuronal Interact 2007;7(2):131-43.

[17] Beyranvand M, Mohammadi G. Incidence of hip fracture in Kermanshah, Iran. Arch Osteoporos 2009;4(1-2):67-70.

[18] Zamani M, Zamani V, Heidari B, et al. Prevalence of osteoporosis with the World Health Organization diagnostic criteria in the Eastern Mediterranean Region: a systematic review and meta-analysis. Arch Osteoporos 2018;13(1):129.

[19] Moher D, Liberati A, Tetzlaff J, et al. Preferred reporting items for systematic reviews and metaanalyses: the PRISMA statement. PLoS Med 2009;6(7):e1000097.

[20] Ahmadi-Abhari S, Moayyeri A, Abolhassani F. Burden of hip fracture in Iran. Calcified Tissue Int 2007;80(3):147-53. 
[21] Abolhassani F, Moayyeri A, Naghavi M, et al. Incidence and characteristics of falls leading to hip fracture in Iranian population. Bone 2006;39(2):408-13.

[22] Aliasgarzadeh A, Bahrami A, Ramazani M, et al. Incidence of osteoporotic hip fracture in above 50 year old peoples of Tabriz in years 2004-2006. Iranian Journal of Endocrinology and Metabolism 2009;10(6):563-70.

[23] Sibai AM, Nasser W, Ammar W, et al. Hip fracture incidence in Lebanon: a national registry-based study with reference to standardized rates worldwide. Osteoporos Int 2011;22(9):2499-506.

[24] Al-Nuaim AR, Kremli M, Al-Nuaim M, et al. Incidence of proximal femur fracture in an urbanized community in Saudi Arabia. Calcified Tissue International 1995;56(6):536-8.

[25] Amin S, Achenbach SJ, Atkinson EJ, et al. Trends in fracture incidence: a population-based study over 20 years. J Bone Miner Res 2014;29(3):581-9.

[26] Lucas R, Martins A, Severo M, et al. Quantitative modelling of hip fracture trends in 14 European countries: testing variations of a shared reversal over time. Sci Rep 2017;7(1):3754.

[27] Shukla JJ, Khandekar RB. Magnitude and determinants of osteoporosis in adult population of South Sharqiya region of Oman. Saudi Med J 2008;29(7):984-8.

[28] Brauer CA, Coca-Perraillon M, Cutler DM, et al. Incidence and mortality of hip fractures in the United States. JAMA 2009;302(14):1573-9.

[29] Lewiecki EM, Wright NC, Curtis JR, et al. Hip fracture trends in the United States, 2002 to 2015. Osteoporos Int 2018;29(3):717-22.

[30] Ballane G, Cauley JA, Luckey MM, et al. Secular trends in hip fractures worldwide: opposing trends east versus west. J Bone Miner Res 2014;29(8):1745-55.

[31] Valizadeh M, Mazloomzadeh S, Azizi R. Epidemiology of hip fractures in Zanjan, Iran. Arch Osteoporos 2008;3(1-2):1-5.

[32] Hung WW, Egol KA, Zuckerman JD, et al. Hip fracture management: tailoring care for the older patient. JAMA 2012;307(20):2185-94.
[33] Cauley JA, Chalhoub D, Kassem AM, et al. Geographic and ethnic disparities in osteoporotic fractures. Nat Rev Endocrinol 2014;10(6):338-51.

[34] El Maghraoui A, Sadni S, Jbili N, et al. The discriminative ability of FRAX, the WHO algorithm, to identify women with prevalent asymptomatic vertebral fractures: a cross-sectional study. BMC Musculoskelet Disord 2014;15:365.

[35] Ghafoori S, Keshtkar A, Khashayar P, et al. The risk of osteoporotic fractures and its associating risk factors according to the FRAX model in the Iranian patients: a follow-up cohort. J Diabetes Metab Disord 2014;13(1):93.

[36] McCloskey E, Johansson H, Harvey NC, et al. Management of patients with high baseline hip fracture risk by FRAX reduces hip fractures-a post hoc analysis of the SCOOP study. J Bone Miner Res 2018;33(6):1020-6.

[37] Shepstone L, Lenaghan E, Cooper C, et al. Screening in the community to reduce fractures in older women (SCOOP): a randomised controlled trial. Lancet 2018;391(10122):741-7.

[38] Moayyeri A, Soltani A, Larijani B, et al. Epidemiology of hip fracture in Iran: results from the Iranian multicenter study on accidental injuries. Osteoporos Int 2006;17(8):1252-7.

[39] Pillai A, Eranki V, Shenoy R, et al. Age related incidence and early outcomes of hip fractures: a prospective cohort study of 1177 patients. J Orthop Surg Res 2011;6:5.

[40] Cawthon PM. Gender differences in osteoporosis and fractures. Clin Orthop Relat Res 2011;469(7):1900-5.

[41] Sterling RS. Gender and race/ethnicity differences in hip fracture incidence, morbidity, mortality, and function. Clin Orthop Relat Res 2011;469(7):1913-8.

[42] Berecki-Gisolf J, Smith PM, Collie A, et al. Gender differences in occupational injury incidence. Am J Ind Med 2015;58(3):299-307.

[43] Zamani M, Derakhshan MH, Zamani V, et al. Editorial: the prevalence of Helicobacter pylori infection worldwide-knowns and unknowns. Authors' reply. Aliment Pharmacol Ther 2018;47(9):1331-2. 